\title{
Ground Juniperus pinchotii and urea in supplements fed to Rambouillet ewe lambs Part 2: Ewe lamb rumen microbial communities
}

\section{Authors: Suzanne L. Ishaq, Carl J. Yeoman, and T. R. Whitney}

This is a pre-copyedited, author-produced PDF of an article accepted for publication in Journal of Animal Science following peer review. The version of record for, see citation below, is available online at: https://dx.doi.org/10.2527/jas2017.1731.

Ishaq, Suzanne L., Carl J. Yeoman, and T. R. Whitney. "Ground Juniperus pinchotii and urea in supplements fed to Rambouillet ewe lambs Part 2: Ewe lamb rumen microbial communities." Journal of Animal Science 95, no. 10 (December 2017): 4587-4599. DOI: 10.2527/jas2017.1731.

Made available through Montana State University's $\underline{\text { ScholarWorks }}$ scholarworks. montana.edu 


\title{
Ground Juniperus pinchotii and urea in supplements fed to Rambouillet ewe lambs Part 2: Ewe lamb rumen microbial communities ${ }^{1}$
}

\author{
S. L. Ishaq, ${ }^{2}$ C. J. Yeoman, $\dagger$ and T. R. Whitney \\ *Biology and the Built Environment Center, University \\ of Oregon, Eugene 97403; †Department of Animal and Range Sciences, Montana State \\ University, Bozeman 59717; and †Texas A\&M AgriLife Research, 7887 U.S. Hwy 87 N., San Angelo 76901
}

\begin{abstract}
This study evaluated effects of ground redberry juniper (Juniperus pinchotii) and urea in dried distillers grains with solubles-based supplements fed to Rambouillet ewe lambs $(n=48)$ on rumen physiological parameters and bacterial diversity. In a randomized study (40 d), individually-penned lambs were fed ad libitum ground sorghum-sudangrass hay and of 1 of 8 supplements $(6$ lambs/treatment; $533 \mathrm{~g} / \mathrm{d}$; as-fed basis) in a $4 \times 2$ factorial design with 4 concentrations of ground juniper $(15 \%, 30 \%, 45 \%$, or $60 \%$ of DM) and 2 levels of urea (1\% or $3 \%$ of DM). Increasing juniper resulted in minor changes in microbial $\beta$-diversity (PERMANOVA, pseudo $\mathrm{F}=1.33, P=$ 0.04); however, concentrations of urea did not show detectable broad-scale differences at phylum, family, or genus levels according to ANOSIM $(P>0.05)$, AMOVA $(P>0.10)$, and PERMANOVA $(P>0.05)$. Linear discriminant analysis indicated some genera were specific to certain dietary treatments $(P<0.05)$, though none of these genera were present in high abundance; high concentrations of juniper were associated with Moraxella and Streptococcus, low concentrations of urea were associated with Fretibacterium, and high concentrations of urea were associated
\end{abstract}

with Oribacterium and Pyramidobacter. Prevotella were decreased by juniper and urea. Ruminococcus, Butyrivibrio, and Succiniclasticum increased with juniper and were positively correlated (Spearman's, $P<0.05)$ with each other but not to rumen factors, suggesting a symbiotic interaction. Overall, there was not a juniper $\times$ urea interaction for total VFA, VFA by concentration or percent total, $\mathrm{pH}$, or ammonia $(P>$ 0.29). When considering only percent inclusion of juniper, ruminal $\mathrm{pH}$ and proportion of acetic acid linearly increased $(P<0.001)$ and percentage of butyric acid linearly decreased $(P=0.009)$. Lamb ADG and G:F were positively correlated with Prevotella (Spearman's, $P<0.05$ ) and negatively correlated with Synergistaceae, the BS5 group, and Lentisphaerae. Firmicutes were negatively correlated with serum urea nitrogen, ammonia, total VFA, total acetate, and total propionate. Overall, modest differences in bacterial diversity among treatments occurred in the abundance or evenness of several OTUs, but there was not a significant difference in OTU richness. As diversity was largely unchanged, the reduction in ADG and lowerend BW was likely due to reduced DMI rather than a reduction in microbial fermentative ability.

Key words: juniper, lamb, microbial ecology, supplement, urea

\footnotetext{
${ }^{1}$ This work was partially supported by the USDA National Institute of Food and Agriculture Hatch Project \#205866 and the Food and Fibers Research Grant Program administered by the Texas Department of Agriculture. Authors would like to thank POET Nutrition (Sioux Falls, SD) for donating dried distillers grains with solubles and Laura Cersosimo, University of Vermont, for assistance with $\mathrm{R}$ coding.

${ }^{2}$ Corresponding author: sueishaq@uoregon.edu

Received May 16, 2017.

Accepted August 5, 2017.
}

\section{INTRODUCTION}

In the southern and southwestern United States, there is a growing interest in using juniper (Juniperus spp.) as a roughage ingredient (Whitney et al., 2011), a forage that is available year-round. However, there is a lack of information on the quality of juniper as a feed source and its effects on animal performance, fermentation, and microbial diversity (Chaves et 
Table 1. Ingredient and chemical composition (\% DM basis) of treatment supplements ${ }^{1}$

\begin{tabular}{|c|c|c|c|c|c|c|c|c|}
\hline \multirow[b]{2}{*}{ Item $^{2}$} & \multicolumn{8}{|c|}{ Supplement ${ }^{3}$} \\
\hline & J15U1 & J15U3 & J30U1 & J30U3 & J45U1 & J45U3 & J60U1 & J60U3 \\
\hline \multicolumn{9}{|l|}{ Ingredient, \% } \\
\hline Ground juniper & 15 & 15 & 30 & 30 & 45 & 45 & 60 & 60 \\
\hline DDGS & 77 & 75 & 62 & 60 & 47 & 45 & 32 & 30 \\
\hline Molasses, cane & 6 & 6 & 6 & 6 & 6 & 6 & 6 & 6 \\
\hline Mineral premix & 1 & 1 & 1 & 1 & 1 & 1 & 1 & 1 \\
\hline Urea & 1 & 3 & 1 & 3 & 1 & 3 & 1 & 3 \\
\hline \multicolumn{9}{|c|}{ Nutrient composition, $\%$} \\
\hline $\mathrm{CP}$ & 26.2 & 29.5 & 23.0 & 26.8 & 20.4 & 23.5 & 16.5 & 21.1 \\
\hline ADICP & 1.9 & 1.9 & 2.0 & 2.1 & 2.2 & 1.9 & 2.0 & 1.7 \\
\hline NDF & 26.4 & 25.7 & 28.2 & 28.4 & 28.7 & 30.9 & 33.5 & 32.0 \\
\hline $\mathrm{ADF}$ & 10.4 & 10.2 & 13.7 & 14.0 & 16.3 & 17.0 & 20.8 & 20.3 \\
\hline Crude fat & 9.2 & 9.2 & 8.6 & 8.3 & 8.0 & 7.5 & 6.9 & 6.9 \\
\hline Lignin & 5.8 & 6.1 & 7.2 & 7.3 & 9.3 & 8.6 & 11.2 & 10.8 \\
\hline $\mathrm{Ca}$ & 0.32 & 0.31 & 0.58 & 0.56 & 0.81 & 0.83 & 1.10 & 1.14 \\
\hline $\mathrm{P}$ & 0.81 & 0.77 & 0.67 & 0.66 & 0.55 & 0.53 & 0.40 & 0.40 \\
\hline Ash & 4.7 & 4.9 & 5.3 & 4.5 & 5.9 & 5.7 & 5.6 & 5.8 \\
\hline Volatile oil & 0.05 & 0.06 & 0.10 & 0.12 & 0.12 & 0.10 & 0.11 & 0.17 \\
\hline \multicolumn{9}{|l|}{$\mathrm{CT}$} \\
\hline Extractable & 0.07 & 0.12 & 0.66 & 0.80 & 1.39 & 1.26 & 1.91 & 2.13 \\
\hline Protein-bound & 0.24 & 0.22 & 0.50 & 0.54 & 0.65 & 0.58 & 1.15 & 1.23 \\
\hline Fiber-bound & 0.12 & 0.07 & 0.15 & 0.13 & 0.17 & 0.23 & 0.18 & 0.33 \\
\hline Total & 0.43 & 0.41 & 1.31 & 1.47 & 2.21 & 2.07 & 3.24 & 3.69 \\
\hline
\end{tabular}

${ }^{1}$ Data in this table were also published in a companion paper (Whitney, 2017).

${ }^{2} \mathrm{~A} 4 \times 2$ factorial arrangement with 4 concentrations of ground juniper $(15 \%, 30 \%, 45 \%$, or $60 \%$ of DM) and 2 concentrations of urea ( $1 \%$ or $3 \%$ of $\mathrm{DM}$ ); dried distillers grains with solubles were replaced as the percentage of juniper increased. DDGS = corn dried distillers grains with solubles; ADICP = acid detergent insoluble $\mathrm{CP} ; \mathrm{CT}=$ condensed tannins; Volatile oil = steam distilled.

${ }^{3}$ Supplements were nonagglomerated.

al., 2008; Whitney et al., 2014; Yesilbag et al., 2016). Juniper can be used as an organic antimicrobial agent in ruminants (Chaves et al., 2008) due to its plant secondary compounds (PSC), including condensed tannins (CT) and terpenes (Karchesy, 1998; Whitney et al., 2014; Stewart et al., 2015) that have been shown to modify rumen physiology and microorganisms (Wallace, 2004; Calsamiglia et al., 2007). Specifically, redberry juniper extract increases the efficacy of ivermectin (Armstrong et al., 2013; Whitney et al., 2013).

Essential oils from juniper and other plants affect rumen microbial density and diversity (Dawdy et al., 2009; Patra and Yu, 2015; Yesilbag et al., 2016), including the reduction of proteo-, amylo-, and fibrolytic genera (Patra and $\mathrm{Yu}, 2012$; Cobellis et al., 2016; Yesilbag et al., 2016). However, the extent of the effects is largely dependent on the species of juniper (Schwartz et al., 1980; Stewart et al., 2015), feed processing (Koedam and Looman, 2008), and species of ruminant (Pritz et al., 1997), as wild ruminants have some physiological adaptations that allow for resistance to PSC that many domestic livestock lack (Austin et al., 1989; Boyle et al., 1999; Dearing et al., 2005). Despite the interest in feeding juniper to livestock, there is a paucity of work on its effect on the di- versity of rumen microorganisms. In the present study, it was hypothesized that feeding different concentrations of redberry juniper and urea would have a significant effect on the diversity of rumen bacteria in ewe lambs.

\section{MATERIALS AND METHODS}

\section{Animals and Management}

Experimental protocol was approved by the Texas A\&M University Institutional Animal Care and Use Committee. Rambouillet ewe lambs $(n=48)$, approximately 8 mo of age, were stratified by BW (initial average BW $37.9 \mathrm{~kg} \pm 3.4 \mathrm{~kg}$ ) and randomly assigned to a treatment. Lambs were housed in individual pens with automatic watering systems and feed bunks, adapted from pasture to 1 of 8 diet treatments, and then maintained on the diet treatment for $40 \mathrm{~d}$. Ground sorghum-sudangrass hay was used as the ad libitum basal diet throughout the trial in an attempt to simulate winter rangeland foraging conditions. Nonagglomerated dried distillers grains with solubles (DDGS)-based supplements (6 lambs/ treatment; $533 \mathrm{~g} / \mathrm{d}$; as-fed basis; Table 1) were added to the basal diet. A $4 \times 2$ factorial arrangement of treat- 
ments was used, with factors being 4 concentrations of ground juniper $(15 \%, 30 \%, 45 \%$, or $60 \%$ of DM) and 2 concentrations of urea $(1 \%$ or $3 \%$ of DM).

\section{Sample Collection, Measurements, and Statistical Analysis}

Juniper and Hay Processing. Details related to juniper and hay processing are reported in a companion paper (Whitney, 2017). In summary, branches less than $3.6 \mathrm{~cm}$ in diameter were cut from mature standing $J$. pinchotii trees, chipped, mechanically dried to approximately $93 \% \mathrm{DM}$, and hammermilled. Sorghumsudangrass hay was only hammermilled.

Ruminal Fluid Collection and Analysis. On d 34, rumen fluid was collected from each lamb, using an oral stomach tube and vacuum pump $4 \mathrm{~h}$ after feeding from 3 randomly selected lambs/treatment; the other 3 lambs/ treatment were sampled the following d. Fluid was filtered through 4 layers of cheesecloth into prewarmed thermoses purged with $\mathrm{CO}_{2}$ and the $\mathrm{pH}$ of a subsample was immediately recorded with a handheld $\mathrm{pH}$ meter (sympHony SP70P; VWR International, Radnor, PA). A subsample was collected, immediately placed on ice, and stored at $-80^{\circ} \mathrm{C}$ to evaluate microbial diversity. Additional subsamples $(1 \mathrm{~mL})$ were acidified with $4 \mathrm{~mL}$ of $0.1 \mathrm{~N} \mathrm{HCl}$ (Farmer et al., 2004) and stored at $-80^{\circ} \mathrm{C}$ for analysis of ammonia $\mathrm{N}$ and VFA. Ammonia $\mathrm{N}$ was analyzed using a Beckman Coulter DU640 spectrophotometer (Beckman Instruments, Inc., Fullerton, CA) according to the Berthelot reaction (phenol-hypochlorite) described by Broderick and Kang (1980). The VFA were analyzed by an Agilent $6890 \mathrm{~N}$ gas chromatograph (Agilent Technology, Inc., Wilmington, DE; Baumgardt, 1964; Fritz and Schenk, 1979).

DNA Extraction and Sequencing. Nucleic acids were extracted from rumen samples using a previously published protocol (Ishaq et al., 2017). Briefly, the PowerSoil 96-well Soil DNA Isolation Kit (MoBio Laboratories, Inc., Carlsbad, CA) was used following kit instructions for centrifugation exclusively and utilizing the kit-directed bead-beating step for mechanical lysis. The PCR amplification of the V3-V4 region of the prokaryotic 16S rRNA gene was performed using the KAPA HotStart PCR Kit (Kapa Biosystems, Wilmington, MA) using a previously described mix and protocol (Ishaq et al., 2017), with primers $341 \mathrm{~F}$ 5'-CCTACGGGAGGCAGCAG-3' (Muyzer et al., 1993) and806R5'-GGACTACHVGGGTWTCTAAT-3 (Caporaso et al., 2011). Amplicon concentration was checked on a TapeStation Bioanalyzer (Agilent Technologies, Santa Clara, CA) and pooled at $2 \mathrm{ng}$ of DNA/sample. Pooled PCR product was run on an agarose gel (Ishaq et al., 2017) and purified using the QIAquick gel extraction kit (QIAGEN, Valencia, CA) according to kit instructions. An Illumina MiSeq (Illumina, San Diego, CA) with a 500-cycle kit was used for high-throughput sequencing, which was the most advanced kit available at the time of sequencing.

DNA Analysis. Sequence data are available in the Sequence Read Archive (SRA) through NCBI under the Bioproject accession PRJNA301719. Contiguous sequences (contig) were created using paired-end $16 \mathrm{~S}$ rRNA sequences for each sample, using the program PANDAseq (Masella et al., 2012) with a simple Bayesian algorithm; however, even after quality control steps (described below), contig analysis resulted in poorer quality taxonomic classification, though it did not affect operational taxonomic unit (OTU) statistical analysis. Therefore, only the forward sequence was used for the final analysis. Sequences per sample ranged from 6,213 to 2,909,211 (median 36,063) prior to quality assurance steps, and the 5 samples that contained greater than 300,000 reads were subsampled down to 300,000 to reduce computing time.

Sequences containing homopolymers $>8$ bases (b) long were trimmed using an in-house script and parsed by quality using mothur ver. 1.36 (Schloss et al., 2009; Kozich et al., 2013) by culling sequences, which were $<200 \mathrm{~b}$ or $>252 \mathrm{~b}$, had a qscore $<30$ for any base, or which contained any ambiguous bases (N). The Silva v119 reference database (Quast et al., 2013), containing approximately $150,00016 \mathrm{~S}$ rRNA bacterial and archaeal sequences, was used as the template to align candidate sequences using the Wang algorithm with a confidence cutoff of $80 \%$ similarity (Wang et al., 2007). The mothur-integrated version of UCHIME was used to identify and remove chimeras (Edgar et al., 2011). The Silva v119 taxonomy database was also used to classify all sequences, and any that would not classify to phylum were removed.

Sequences per sample ranged from 5,406 to 287, 107 (median 32,623) after quality assurance and were subsampled to 5,000 reads per sample for statistical analysis, and binned into OTUs (including several OTU of bacteria unclassified at the genus level that were binned at a higher level of taxonomy for each group) based on the genus-level taxonomy of each sequence (phylotyping of taxa groups; Chen et al., 2013). The following diversity measures are presented as group means using the mothur-integrated versions: ACE (Chao and Shen, 2003), CHAO (Chao and Shen, 2010), Jackknife (Burnham and Overton, 1979), Inverse Simpson (Jost, 2006), Good's Coverage (Good, 1953), ShannonWeiner diversity (Shannon and Weaver, 1949), Analysis of Molecular Variance (AMOVA), and UniFrac unweighted (structure only) and weighted (structure and abundance) values (Lozupone and Knight, 2005). 
Table 2. Genus-level diversity indices for rumen bacterial diversity from ewe lambs on juniper (J) or urea (U) supplementation by $\% \mathrm{DM}$

\begin{tabular}{lllllll}
\hline \hline Group mean & $\mathrm{CHAO}^{1}$ & $\mathrm{ACE}^{1}$ & Good's coverage $^{\mathrm{a}}$ & $\mathrm{OTU}^{2}$ & Inverse Simpson & Shannon-Weiner diversity \\
\hline J15U1 & $114^{\mathrm{a}, \mathrm{b}}$ & $116^{\mathrm{a}, \mathrm{b}, \mathrm{d}}$ & $0.995^{\mathrm{a}, \mathrm{b}, \mathrm{e}}$ & $85^{\mathrm{acd}}$ & $3.69^{\mathrm{ab}}$ & $2.15^{\mathrm{abc}}$ \\
J15U3 & 120 & 119 & $0.995^{\mathrm{c}}$ & $91^{\mathrm{b}}$ & 4.92 & 2.34 \\
J30U1 & 128 & $141^{\mathrm{a}, \mathrm{e}}$ & $0.994^{\mathrm{a}, \mathrm{f}}$ & $96^{\mathrm{ae}}$ & $4.56^{\mathrm{a}}$ & $2.374^{\mathrm{a}}$ \\
J30U3 & 125 & 138 & 0.994 & $98^{\mathrm{b}}$ & 4.82 & 2.412 \\
J45U1 & $135^{\mathrm{a}}$ & $145^{\mathrm{b}, \mathrm{c}}$ & $0.994^{\mathrm{b}, \mathrm{d}}$ & $97^{\mathrm{c}}$ & $5.3^{\mathrm{b}}$ & $2.43^{\mathrm{b}}$ \\
J45U3 & 110 & $104^{\mathrm{c}, \mathrm{e}}$ & $0.996^{\mathrm{c}, \mathrm{d}, \mathrm{f}}$ & $84^{\mathrm{e}}$ & 5.33 & 2.338 \\
J60U1 & $138^{\mathrm{b}, \mathrm{c}}$ & $156^{\mathrm{d}}$ & $0.994^{\mathrm{e}}$ & $102^{\mathrm{d}}$ & 4.32 & $2.366^{\mathrm{c}}$ \\
J60U3 & $115^{\mathrm{c}}$ & 127 & 0.995 & 93 & 4.948 & 2.346 \\
\hline
\end{tabular}

${ }^{\mathrm{a}-\mathrm{f} W i t h i n ~ e a c h ~ c o l u m n, ~ s i g n i f i c a n t l y ~ d i f f e r e n t ~} t$ test comparisons $(P<0.05)$ are indicated by matching letters.

${ }^{1}$ Abundance-based coverage estimators.

${ }^{2}$ Operational taxonomic units.

Linear Discriminant Analysis (LDA) was used to detect discriminatory OTU in diet treatments, using the Wilcox Rank Test to determine statistical significance. PRIMER ver. 6 (Clarke, 2006) was used to analyze OTU abundance data, which was normalized to relative abundance and was square-root transformed. The PERMANOVA assessed which treatment contributed to data variation, analysis of similarity (ANOSIM) was used to test sample similarity, and principal coordinate(s) analysis (PCoA) and non-metric multidimensional scaling (NMDS) plot with vectors representing multiple regressions to show correlation coefficients were calculated using PERMANOVA. A correlation matrix plot of significant $(P<0.05)$ Spearman's rank correlations was made using R (R Core Team, 2015).

Statistical Analysis of Rumen Fluid Characteristics. Ruminal fluid volatile fatty acids, ammonia $\mathrm{N}$, and $\mathrm{pH}$ were analyzed using the PROC GLIMMIX procedure of SAS with a normal distribution. The model included juniper concentration, urea concentration, and juniper $\times$ urea interaction. Individual lamb was the subject and Kenward-Rodger approximation was used. Data are reported as least squares means with greatest standard errors. Suitable covariance structures were compared for each model and compound symmetry heterogeneity was determined to be the most appropriate for all variables. Treatment effects were tested using linear and quadratic orthogonal contrasts. The SAS Proc IML procedure was used to generate orthogonal contrast coefficients; only the greatest order contrast $(P<0.05)$ was discussed.

\section{RESULTS}

Chemical composition of treatment diets (Table 1) and a more detailed discussion of differences in fiber, protein, and plant secondary compounds can be located in a companion paper (Whitney, 2017). In summary, as ground juniper replaced DDGS, supplemental nutrient quality declined and total CT increased; volatile terpene oil concentration slightly increased, but less than $0.17 \%$ of DM was observed in any of the supplements. A companion paper (Whitney, 2017) reported that lambs fed the $60 \%$ ground juniper supplement had reduced supplement DMI and that hay and total DMI were variable by $\mathrm{d}$ for all lambs. Furthermore, lamb BW showed a juniper $\times \mathrm{d}$ interaction and for lambs receiving $60 \% \mathrm{DM}$ juniper $(P<0.001)$, the quadratic trend for BW was influenced by reduced ADG (linear decrease, $P<0.001$ ). Urea at $3 \%$ vs. $1 \%$ DM tended to have reduced end BW $(P=0.06)$, but similar ADG and G:F $(P>0.17)$.

Treatment (juniper or urea concentration, or juniper $\times$ urea interactions) effects on OTU $\beta$-diversity were not observed using ANOSIM $(P>0.05)$ or AMOVA $(P>0.10)$. Juniper concentrations did increase OTU $\beta$-diversity $(\mathrm{df}=3$, pseudo $\mathrm{F}=1.33, P=$ 0.04, PERMANOVA; Table 2), but urea or juniper $\times$ urea interactions did not PERMANOVA $(P>0.05)$. Treatments did not produce significantly different similarity dendograms in terms of tree structure by bacterial membership ( $P>0.05$, unweighted UniFrac). However, some small, yet significant, pairwise comparisons were seen when accounting for abundance of the bacterial membership using weighted UniFrac (Table 3).

The PCoA revealed Prevotella (Otu001) and BS11 gut group (Otu005) had Pearson's correlations greater than 0.75 , and both contributed to the $16.8 \%$ and $8.3 \%$ of total variation seen in $\mathrm{PC} 1$ and $\mathrm{PC} 2$, respectively (Fig. 1A). However, diet treatments did not produce significant clustering (Fig. 1B). Similarly, this lack of overall change in bacterial diversity was reflected in the nMDS plot of Bray-Curtis Dissimilarity (data not shown), as there was no significant clustering by diet or specific supplements. Using nMDS, Prevotella (Otu001), Ruminococcus (Otu015), and Butyrivibrio (Otu018) exhibited significant correlations $\left(R^{2}>0.75\right.$, Pearson's).

A total of 292 genus-level OTU were detected, 30 of which were found in all samples. Alpha-diversity indices are presented in Table 2; J15U1, J30U1, and J45U1 
Table 3. Pairwise comparisons of similarity dendograms using Weighted UniFrac from ewe lambs on juniper $(\mathrm{J})$ or urea $(\mathrm{U})$ supplementation by percentage of $\mathrm{DM}^{1}$

\begin{tabular}{|c|c|c|}
\hline Group & Weighted UniFrac score & $P$-value \\
\hline J15U1- J30U1 & 0.600058 & $<0.001$ \\
\hline J15U3- J30U1 & 0.515641 & $<0.001$ \\
\hline J15U1- J30U3 & 0.623863 & $<0.001$ \\
\hline J15U3- J30U3 & 0.492495 & 0.02 \\
\hline J30U1- J30U3 & 0.58918 & 0.002 \\
\hline J15U1- J45U1 & 0.382344 & $<0.001$ \\
\hline J15U3- J45U1 & 0.404767 & 0.002 \\
\hline J30U1- J45U1 & 0.429141 & $<0.001$ \\
\hline J30U3- J45U1 & 0.447524 & 0.02 \\
\hline J15U1- J45U3 & 0.25941 & $<0.001$ \\
\hline J15U3- J45U3 & 0.251888 & 0.008 \\
\hline J30U1- J45U3 & 0.283052 & $<0.001$ \\
\hline J30U3- J45U3 & 0.288522 & 0.02 \\
\hline J45U1- J45U3 & 0.270442 & 0.02 \\
\hline J15U1- J60U1 & 0.315606 & $<0.001$ \\
\hline J15U3- J60U1 & 0.39026 & 0.01 \\
\hline J30U1- J60U1 & 0.325795 & 0.03 \\
\hline J30U3- J60U1 & 0.433791 & 0.04 \\
\hline J45U1- J60U1 & 0.328127 & 0.02 \\
\hline J45U3- J60U1 & 0.210389 & 0.06 \\
\hline J15U1- J60U3 & 0.486942 & $<0.001$ \\
\hline J15U3- J60U3 & 0.275403 & 0.11 \\
\hline J30U1- J60U3 & 0.504252 & $<0.001$ \\
\hline J30U3- J60U3 & 0.483684 & 0.01 \\
\hline J45U1- J60U3 & 0.380139 & 0.005 \\
\hline J45U3- J60U3 & 0.267211 & 0.008 \\
\hline J60U1- J60U3 & 0.411652 & 0.01 \\
\hline \multicolumn{3}{|l|}{ Juniper } \\
\hline $15 \%-30 \%$ of $\mathrm{DM}$ & 0.395656 & 0.002 \\
\hline $15 \%-45 \%$ of $\mathrm{DM}$ & 0.216567 & $<0.001$ \\
\hline $30 \%-45 \%$ of $\mathrm{DM}$ & 0.218012 & 0.005 \\
\hline $15 \%-60 \%$ of $\mathrm{DM}$ & 0.283583 & 0.02 \\
\hline $30 \%-60 \%$ of $\mathrm{DM}$ & 0.297579 & 0.08 \\
\hline $45 \%-60 \%$ of $\mathrm{DM}$ & 0.201323 & 0.002 \\
\hline \multicolumn{3}{|l|}{ Urea } \\
\hline $1 \% \mathrm{DM}-3 \% \mathrm{DM}$ & 0.184663 & $<0.001$ \\
\hline
\end{tabular}

${ }^{1} \mathrm{~A} 4 \times 2$ factorial arrangement with 4 concentrations of ground juniper $(15 \%, 30 \%, 45 \%$, or $60 \%$ of DM) and 2 concentrations of urea $(1 \%$ or $3 \%$ of DM); dried distillers grains with solubles were replaced as the percentage of juniper increased.

were most dissimilar from the other groups, while J30U3, J60U3, and J15U3 were most similar to the other groups.

Supplementation with juniper and urea caused only modest changes in the taxonomic profiles at the family (Fig. 2) and genus levels (Fig. 3). The families Prevotellaceae and BS11 gut group (Bacteroidetes) decreased with increasing concentrations of juniper at $1 \%$ and $3 \%$ urea, respectively, while families Acidaminococcaceae and S24-7 increased. Ruminococcaceae increased slightly at medium juniper concentrations, but not at high concentrations
Table 4. Discriminatory rumen bacterial taxa from ewe lambs on juniper and urea supplementation treatments using linear discriminant analysis (LDA) ${ }^{1}$

\begin{tabular}{llcc}
\hline \hline Taxa & \multicolumn{1}{c}{ Group } & LDA & $P$-value \\
\hline Histophilus & J15U1 & 2.871 & 0.04 \\
Mycoplasma & J15U3 & 2.012 & 0.004 \\
Flavobacteriaceae & J15U3 & 2.015 & 0.02 \\
Clostridiales & J30U3 & 2.031 & 0.04 \\
RF9 (Mollicutes) & J30U3 & 3.719 & 0.02 \\
Howardella & J60U1 & 2.122 & 0.005 \\
Streptococcus & J60U1 & 2.946 & 0.001 \\
Moraxella & J60U3 & 2.639 & 0.008 \\
Bacteroidetes & J60U3 & 3.994 & 0.01 \\
Oribacterium & J60U3 & 2.733 & 0.01 \\
Mogibacterium & Juniper 30\% of DM & 2.323 & 0.02 \\
Lachnospiraceae & Juniper 45\% of DM & 2.912 & 0.04 \\
Moraxella & Juniper 60\% of DM & 2.516 & 0.004 \\
Streptococcus & Juniper 60\% of DM & 2.727 & 0.005 \\
Fretibacterium & Urea 1\% of DM & 2.355 & 0.009 \\
Firmicutes & Urea 1\% of DM & 3.094 & 0.01 \\
Oribacterium & Urea 3\% of DM & 2.525 & 0.001 \\
Verrucomicrobia & Urea 3\% of DM & 2.436 & 0.02 \\
Pyramidobacter & Urea 3\% of DM & 2.316 & 0.02 \\
\hline
\end{tabular}

${ }^{1}$ Significance $(P<0.05)$ was determined with a Wilcox Rank test. A $4 \times 2$ factorial arrangement with 4 concentrations of ground juniper $(15 \%$, $30 \%, 45 \%$, or $60 \%$ of DM) and 2 concentrations of urea $(1 \%$ or $3 \%$ of $\mathrm{DM}$ ); dried distillers grains with solubles were replaced as the percentage of juniper increased.

of juniper. Christensenellaceae and Lachnospiraceae increased with juniper supplementation at the lower concentration of urea. Spirochaetaceae, Veillonellaceae, and Rikenellaceae were unchanged. These trends were mirrored in the taxonomic diversity at the genus level. The 25 most abundant genera that were different $(P<$ 0.05 ) between groups are provided in Fig. 3. Relative abundance of Prevotella generally decreased with increasing juniper concentrations, while RC9 gut group increased, independently of urea concentration, although correlations were not very strong by linear regression $\left(R^{2}=0.09\right.$ to 0.34$)$. Succiniclasticum (family Acidaminococcaceae) increased with increasing juniper concentrations at both urea concentrations, with a stronger correlation $\left(R^{2}=0.81\right.$ and 0.40 , respectively).

Taxa that were discriminatory to a particular concentration of juniper or urea, or to a diet, are presented in Table 4. Greater concentrations of juniper were associated with Moraxella and Streptococcus. Lower concentrations of urea were associated with Fretibacterium, while higher concentrations were associated with Oribacterium and Pyramidobacter.

Overall, there was not a juniper $\times$ urea interaction for total VFA, VFA by concentration or percent total, $\mathrm{pH}$, or ammonia concentration $(P>0.29$; Fig. 4$)$. When considering only the increase in urea from $1 \%$ to 

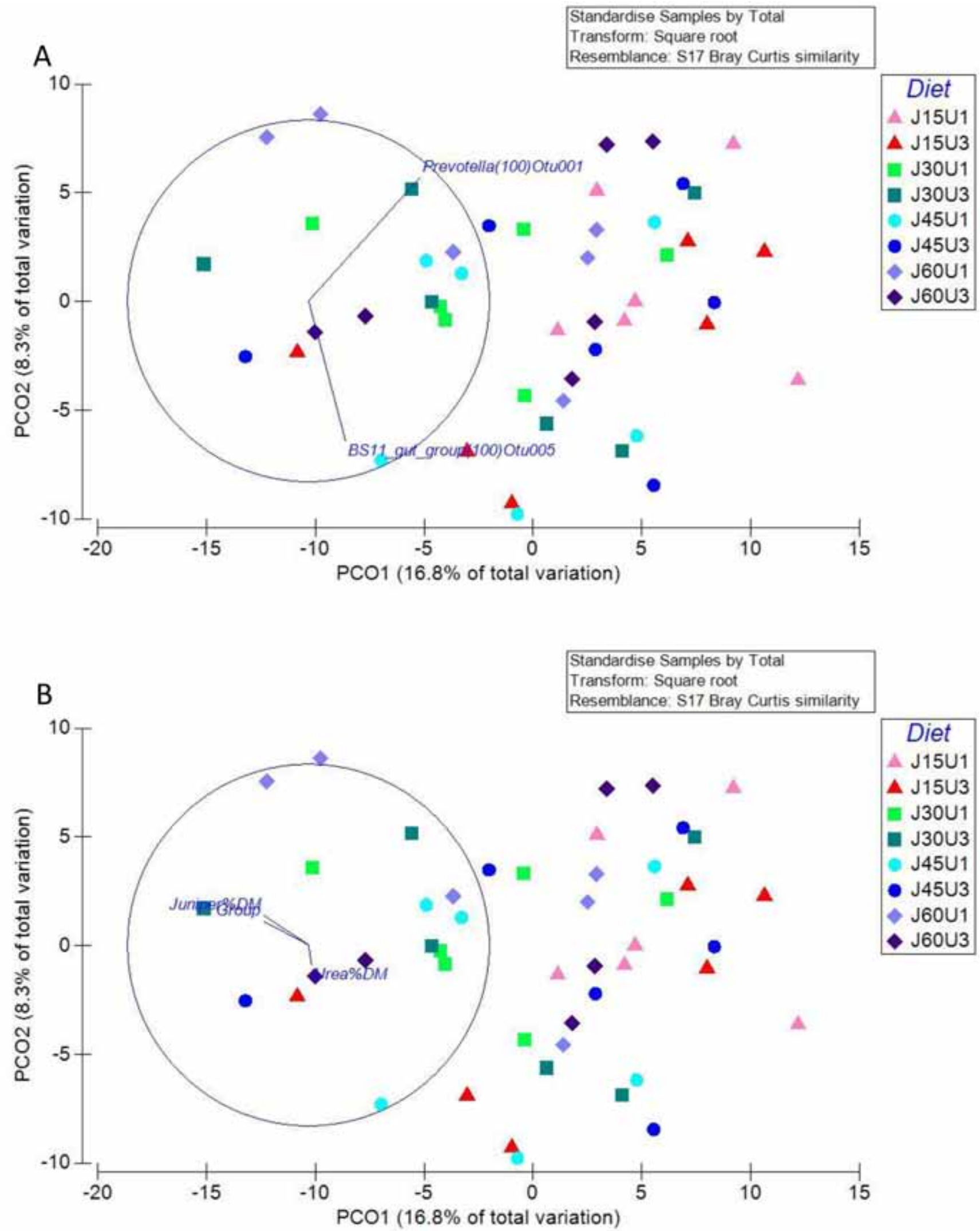

Figure 1. Principal coordinates analysis (PCoA) plot comparing OTU abundance in ewe lamb rumen samples over increasing juniper (J) or urea (U) supplementation by $\%$ DM. Vectors show significant effects (Pearson's correlation $P>0.75$ ) by OTUs (A) and treatment (B), with vector length showing strength of correlation. 

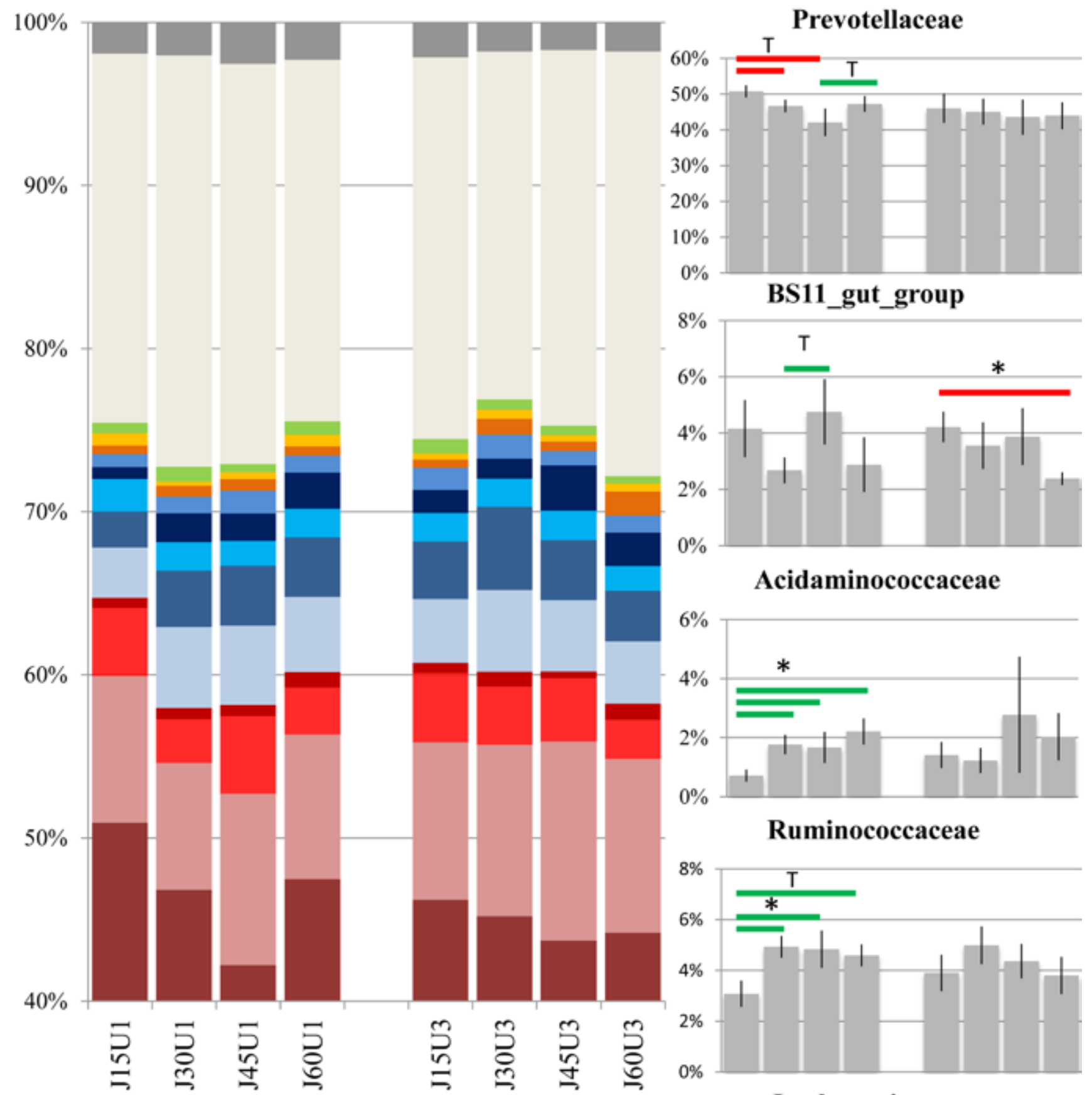

Acidaminococcaceae

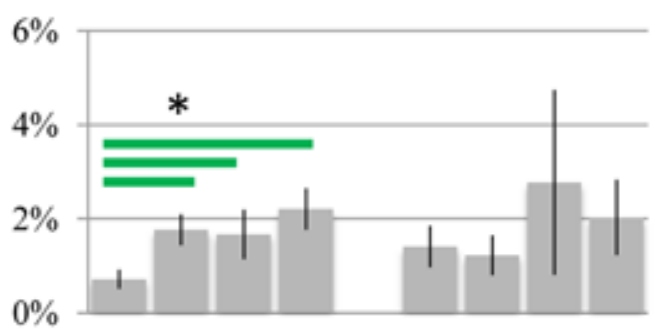

\section{Ruminococcaceae}

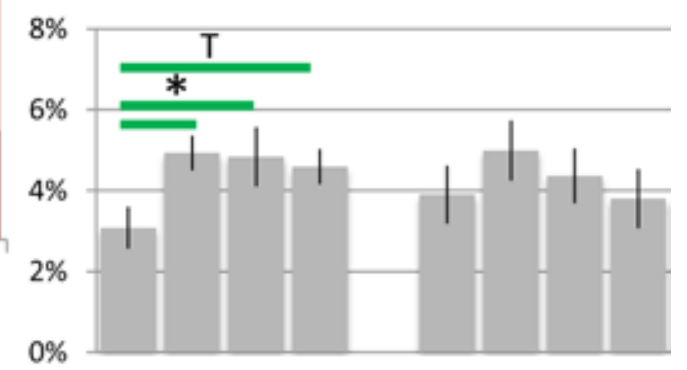

w other

unclassified

" Spirochaetaceae

= Succinivibrionaceae

n Desulfovibrionaceae

n Christensenellaceae

- Acidaminococcaceae

- Lachnospiraceae

- Bacteroidales S24-7

= Rikenellaceae

- Veillonellaceae

n Ruminococcaceae

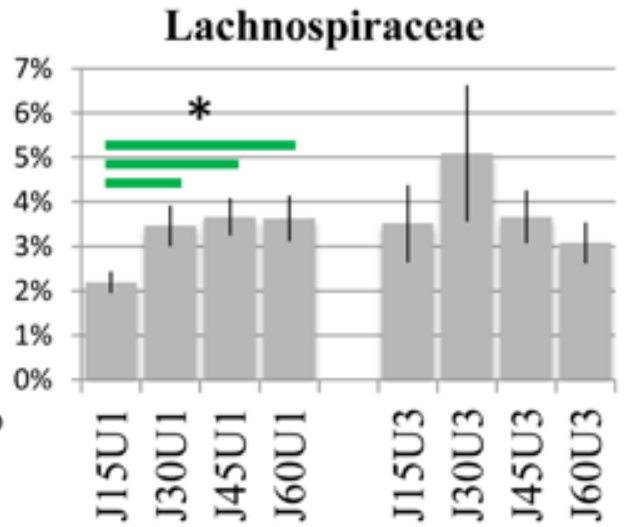

Figure 2. Mean rumen bacterial abundance at the family level for ewe lambs on differing juniper (J) and urea (U) supplementations. Families are color coordinated by phylum: Bacteroidetes $=$ red, Firmicutes $=$ blue, Proteobacteria $=$ orange, Spirochaetae $=$ green, and other $($ dark gray) constitutes families with $<1 \%$ total abundance. Selected bacterial families of important to rumen function appear on the right side with positive (green) and negative (red) changes indicated as significant $\left(P<0.05,{ }^{*}\right)$ or trending $(0.05<P<0.1, \mathrm{~T})$ according to Student's $t$ test. 


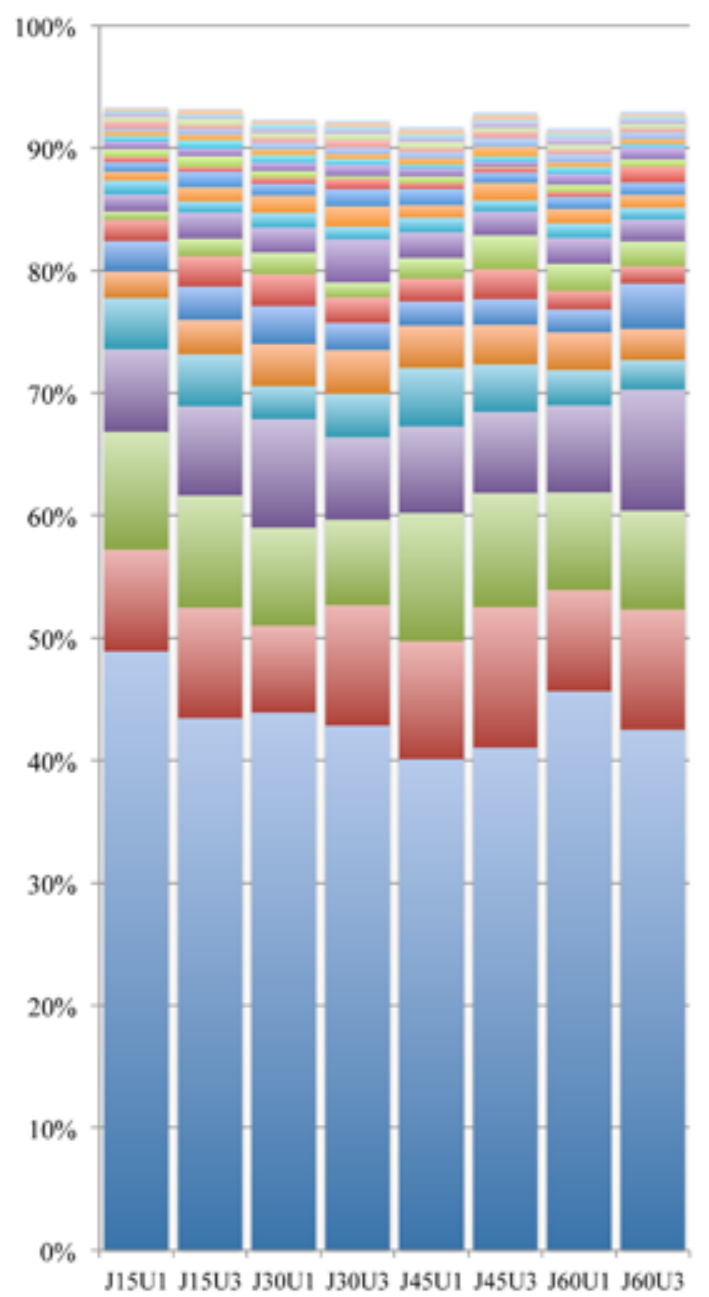

\begin{tabular}{|c|c|c|c|c|c|c|c|c|c|c|c|c|c|c|c|c|}
\hline & $1 \%$ & vs & $3 \% 1$ & Irea & $\frac{A}{\frac{\mathrm{e}}{\mathrm{S}}}$ & & $\frac{6 D}{\rho}$ & $\mathrm{M}$ & Ure & 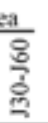 & 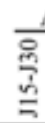 & & $\frac{3 \%}{8}$ & $\frac{D N}{4}$ & & $\frac{\mathrm{ea}}{8}$ \\
\hline & & & & & & & & & & & & & & & & \\
\hline "probable_genus_10 & & & & & & $*$ & & & & & & & & & & \\
\hline Saccharofermentans & & & & & & & & & & & & - & & & & \\
\hline Anaerovibrio & & & & & & & & & & $\cdot$ & & & & & & $\cdot$ \\
\hline unclassified & & & & $*$ & & & & & & & & & & & $* *$ & \\
\hline = uncl_Veillonellaceae & & & & & $\cdot$ & & & $\cdot$ & & $*$ & & & & & & \\
\hline Butyrivibrio & & 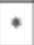 & & & . & $*$ & & $+\infty$ & $*$ & $*$ & & & 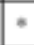 & & & $\cdot$ \\
\hline uncl_Gastranaerophilales & & & & & & & & & & & & & & & $*$ & \\
\hline Treponema & & & & & - & & & $\cdot$ & $\bullet$ & & & & & & & \\
\hline$=$ uncl_S24-7 & & & & & $*$ & & & $*$ & $*$ & & & & & & & \\
\hline Quinella & & & $*$ & & & & & & & & & & & & & \\
\hline = uncl_Desulfovibrionaceae & & & & & $\cdot$ & & & & $*$ & & & & & & & $\cdot$ \\
\hline = uncl_Christensenellaceae & & & $*$ & & & & $*$ & $*$ & & & & & & & & \\
\hline$=$ uncl RF9 & & & & & & & & & & & & & & & $*$ & \\
\hline$=$ uncl Firmicutes & & & $\cdot$ & & & & & & & & $*$ & & & $\cdot$ & & \\
\hline = uncl_Lachnospiraceae & & & & & & & & & & & & $*$ & $*$ & & & \\
\hline = Succiniclasticum & & & 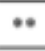 & & & - & $\cdot$ & & & & $*$ & & & & & \\
\hline = uncl Prevotellaceac & & & & & $*$ & & & & & & & $*$ & $=$ & * & & \\
\hline$=$ uncl Bacteroidetes & & & & & $*$ & & & $*$ & $*$ & & & & & & & \\
\hline$=$ une Ruminococcaceae & $\bullet$ & & & & $\cdot$ & & & & $\bullet$ & & & & & & & $\cdot$ \\
\hline$=$ uncl BSII gut group & & & $*$ & & & & & & & & & & & & & \\
\hline$=$ unclassified & & & & & & & & & $*$ & $\cdot$ & & & & & & \\
\hline = unc_Bacteroidales & & & & & $*$ & & & & $*$ & & & & & & & \\
\hline$=R C 9$ gut _group & & & & & & & & & & & & & - & & & \\
\hline$=$ Prevotella & & & & & & & & & $*$ & $*$ & $*$ & & & & $* *$ & \\
\hline
\end{tabular}

Figure 3. Mean rumen bacterial abundance for the most abundant 25 genera which were significant across treatments for ewe lambs on differing juniper $(\mathrm{J})$ and urea $(\mathrm{U})$ supplementations. Significance was determined according to Student's $t$ test $\left(P<0.05, * ; P<0.0,{ }^{* *}\right)$, and taxa are listed in the order in which they appear in the figure.

$3 \%$, there was no effect on total VFA $(P>0.10)$ or $\mathrm{pH}$ $(P>0.89)$. However, when considering the increase in percent inclusion of juniper, ruminal $\mathrm{pH}$ and proportion of acetic acid linearly increased $(P<0.001)$, percentage of propionic acid was unchanged $(P=0.34)$, and percentage of butyric acid linearly decreased $(P=$ 0.009). No differences $(P>0.26)$ were observed for acetic, propionic, or total VFA $(\mathrm{mM})$; however, $\mathrm{mM}$ of butyric acid linearly decreased $(P=0.02)$ as percentage of juniper increased in the diet.

When comparing VFA, diet treatment, as well as blood serum and fecal DM presented in Whitney (2017), several taxa had significant correlations using Spearman's rank test (Fig. 5). Lamb ADG and G:F were positively associated with Prevotella and negatively associated with Synergistaceae, the BS5 group, and Lentisphaerae. Lamb BW was not significantly correlated with any taxon. Lentisphaerae was positively associated with percentage of juniper, as was the RFP12 group, and Firmicutes was negatively associated with percentage of urea. Firmicutes was also negatively associated with serum urea nitrogen (SUN), rumen ammonia, total VFA, total acetate, and total propionate. Despite this, many taxa belonging to the phylum Firmicutes had positive correlations with one another. Prevotella had a large number of negative correlations with other taxa, including the genera Ruminococcus, Butyrivibrio, and Succiniclasticum, which were all positively associated with each other but not to any rumen factors, implying a biotic interaction.

\section{DISCUSSION}

The modest differences in bacterial diversity among treatments of juniper and urea were due to changes in the abundance or evenness of several genera, but there was not a significant difference in genus-level OTU richness. The shortness of the sequence lengths made species-level identification difficult, and the use of a single time-point for diversity sampling precluded any investigation into immediate or transitional changes to rumen bacteria caused by juniper. However, the short- 


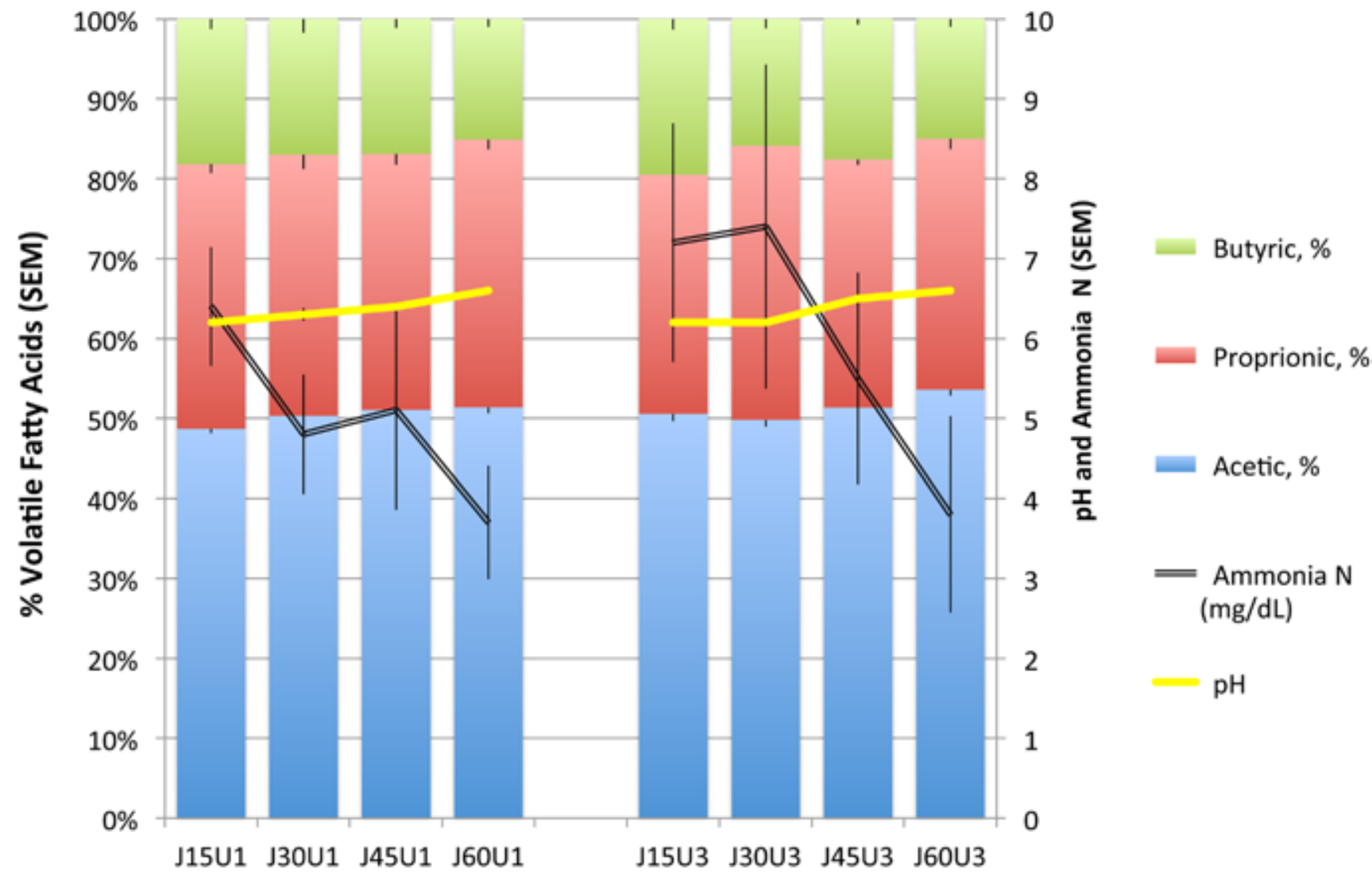

\section{Diet Treatments}

Figure 4. Volatile fatty acid profile, ammonia nitrogen, and $\mathrm{pH}$ for ewe lambs on differing juniper $(\mathrm{J})$ and urea $(\mathrm{U})$ supplementations. Standard error mean bars are shown.

term effects of juniper or other essential oils on ruminants and bacteria have been previously investigated (Patra and Yu, 2012; Patra and Yu, 2015; Yesilbag et al., 2016), as well as rumen diversity restructuring using longer-term or repeated-feeding studies (Kohl and Dearing, 2012; Yesilbag et al., 2016).

As diversity was largely unchanged, the change in production (Whitney, 2017) was likely due more to a reduced feed intake caused by juniper concentration and less from a reduction in microbial fermentative ability. Previous studies have shown that dietary toxins can increase the metabolic cost of thermoregulation (Bozinovic and Novoa, 1997; McLister et al., 2004) and can also reduce body heat loss (Al-Haidary et al., 2001). Herbivores employ feeding strategies to mitigate exposure to PSC (Dearing et al., 2005), such as reducing feed intake, which can also be a management technique (Taylor et al., 1994; Dziba et al., 2006). It is possible that lambs ingesting high concentrations of juniper in Texas during the late summer simply consumed less supplemental diet to reduce toxin- and fermentation-related heat generation, which resulted in the associated reduction in ADG and end BW seen on the $60 \%$ DM juniper concentration diets (Whitney, 2017). It is also possible that lambs were not completely naïve to eating juniper, as they may have consumed some while on range pasture. Likewise, while their dams were not specifically fed juniper, they may have encountered juniper previously, which would have primed their microbiome to reduce effects of juniper during the feeding trial (Kohl and Dearing, 2012).

Previously, supplementation with essential oils (not including juniper oil) affected rumen bacterial density and diversity: Succiniclasticum was reduced by origanum oil, but not affected by garlic or peppermint oils (Patra and Yu, 2015). In the present study, Succiniclasticum was increased with juniper supplementation in a dose-dependent manner. Succiniclasticum was originally isolated from dairy cow rumen digesta, and ferments succinate to proprionate (van Gylswyk, 1995). In the present study, Ruminococcus and Butyrivibrio were also increased as juniper increased. Ruminococcus has previously been shown to produce succinate, and two studies have shown certain strains of Butyrivibrio fibrosolvens to produce succinate as well (Dehority, 1966; Holdeman et al., 1977; Kasperowicz, 1994). Thus, these two genera may contribute to the correlated increase in Succiniclasticum, although it is unclear what might be driving the increase in Ruminococcus and Butyrivibrio in response to juni- 

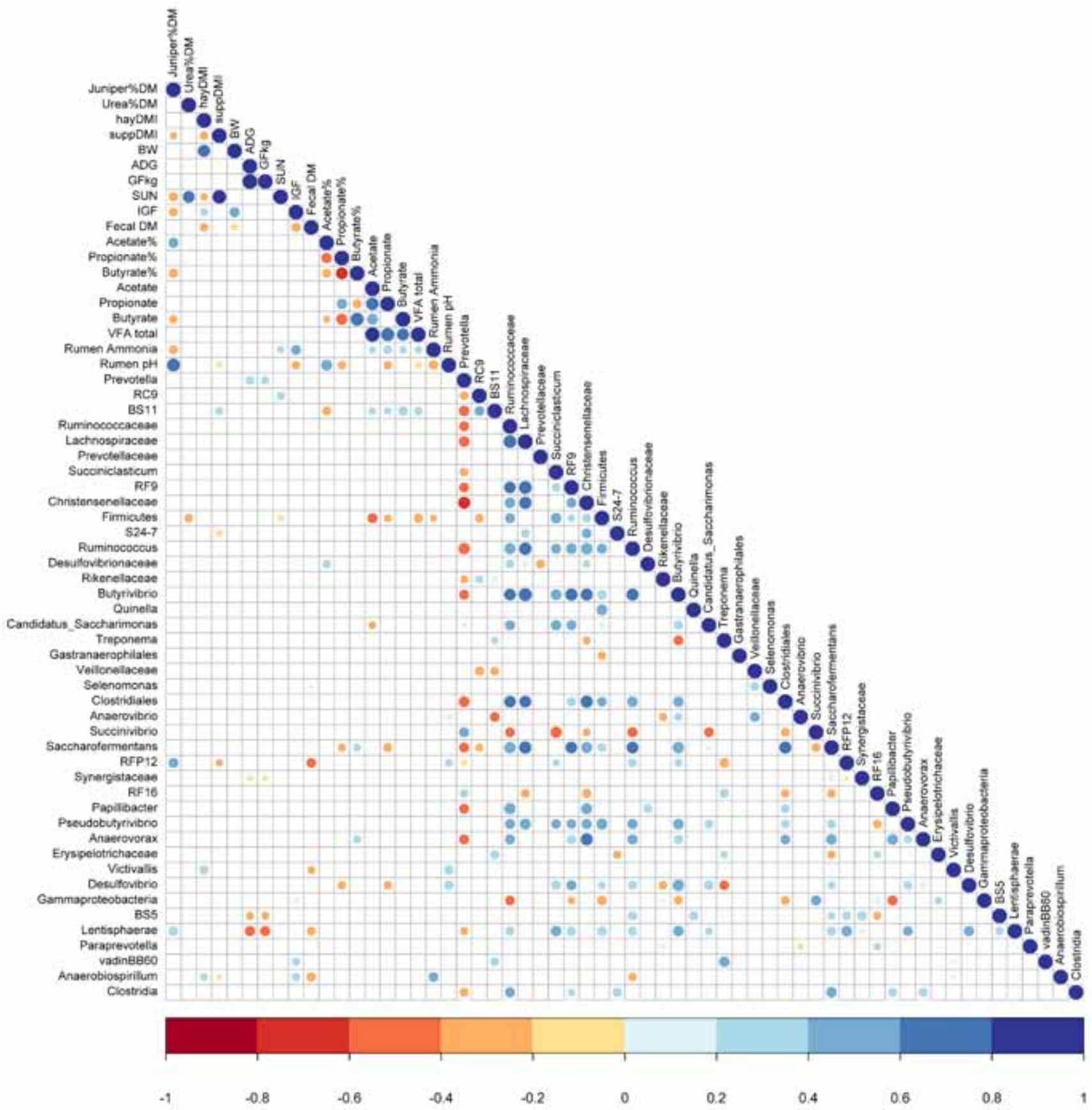

Figure 5. Spearman's rank correlations between the most abundant bacterial taxa, dietary conditions, and lamb physiological parameters, for ewe lambs on differing juniper $(J)$ and urea $(\mathrm{U})$ supplementations. Only significant $(P<0.05)$ correlations are shown and bacterial taxa are listed in order of total abundance.

per supplementation. While both might be increased by the additional dietary NDF and ADF of the juniper diet (Table 1; Whitney, 2017), as juniper berry oil previously increased DM digestion in cattle (Yang et al., 2007), they were also both reduced by other essential oil supplementation (Zhu et al., 2014; Patra and Yu, 2015).

Peppermint oil also increased the proportion of Prevotella (Patra and Yu, 2015), which were sensitive to monoterpenes from rosemary leaves (Cobellis et al., 2016). A reduction in Prevotella can reduce dry matter digestion (Cobellis et al., 2016). In the present study, Prevotella was reduced with an increasing juniper con- centration, as was ADG and end BW (Whitney, 2017), something that has been previously reported in lambs on a $30 \%$ juniper-based feedlot diet (Whitney et al., 2014). As reported in the companion paper, increasing concentrations of juniper or urea did not affect hay or total (hay + supplement) DMI (Whitney, 2017).

Juniper has been shown to contain various monoterpenes including sabinene, camphor, limonene, $\alpha$-pinene, and elemol (Whitney et al., 2014; Stewart et al., 2015). There have been several studies showing the degradation of these compounds in vitro using the bacteria in rumen contents from goats (Broudiscou et 
al., 2007; Malecky and Broudiscou, 2009; Malecky et al., 2012); however, this has not also been shown in sheep, and even inoculation of a sheep rumen with rumen liquor from a goat fed a diet high in plant secondary compounds failed to improve terpene degradation in the sheep (Vaithiyanathan et al., 2005).

Moraxella has previously been isolated from soil and shown to detoxify the PSC fluroacetate using a fluoroacetate dehalogenase enzyme (Gregg et al., 1994); however, it has also been isolated from mucosal surfaces (Segata et al., 2012; Holman et al., 2015), some species of which are considered pathogenic (Dickey et al., 2016). Certain mammals across the globe have been shown to be resistant to toxic PSC, including fluoroacetate (Palo and Robbins, 1991). Streptococcus species are likewise both beneficial and detrimental to ruminants, depending on species and context (Asanuma and Hino, 2002; Babaei et al., 2015). Both genera were increased by juniper.

Urea economically increases dietary nitrogen, which is cycled within the host via diffusion across the rumen wall, reentry in to the rumen via saliva, or through protein produced by gut bacteria (Patra, 2015). Interestingly, Fretibacterium, Oribacterium, and Pyramidobacter were all discriminatory to urea in the diet in the present study, but these species previously identified in the human oral cavity have been shown to be negative for urea hydrolysis (Downes et al., 2009; Segata et al., 2012; Vartoukian et al., 2013; Berger, 2015).

In addition to strategies by the host, the microbiome residing in the digestive tract can provide opportunities to biotransform terpenes and other compounds into nontoxic metabolites (de Carvalho and da Fonseca, 2006; Miller et al., 2014; Kohl and Dearing, 2016). This is largely done using a variety of enzymes, such as the cytochrome P450 family, epoxide hydrolases, or other compound-specific dehydrogenases (Boyle et al., 1999; de Carvalho and da Fonseca, 2006; Lüddeke et al., 2012). Rumen fluid has been shown to contain up to $1,630 \mathrm{nmol} / \mathrm{L} \mathrm{O}_{2}$ prior to eating (Scott et al., 1983) and reactive oxygen species in the rumen can originate from plants or ruminant host tissues due to ingested plant secondary compounds (Quinn et al., 2014). A conferred ability to digest PSC or reduce reactive oxygen species released by the rumen wall may be indicated by the rumen microbial metagenome; however, it was not predicted in this study as current methodology for predictive differences in metagenomics is dependent on differences in population diversity (Langille et al., 2013). Metagenomics or transcriptomics would be required to elucidate any strainspecific or diversity-independent functional changes, especially given that some juniper berry (Juniperus communis L.) has been shown to contain antioxidants
(Elmastaş et al., 2006), which may preclude the need for action against its essential oils.

\section{Conclusion}

Moderately high juniper and urea supplementation over a 40 -d period only caused modest changes in lamb performance and rumen bacterial diversity as compared to low juniper and/or urea. Thus, this feeding strategy could be implemented in livestock production practices to provide low-cost forage (juniper) and $\mathrm{N}$ (urea), while synergistically reducing juniper encroachment and increasing forage production.

\section{LITERATURE CITED}

Al-Haidary, A., D. E. Spiers, G. E. Rottinghaus, G. B. Garner, and M. R. Ellersieck. 2001. Thermoregulatory ability of beef heifers following intake of endophyte-infected tall fescue during controlled heat challenge. J. Anim. Sci. 79:1780-1788. doi: $10.2527 / 2001.7971780 \mathrm{x}$

Armstrong, S. A., D. R. Klein, T. R. Whitney, C. B. Scott, J. P. Muir, B. D. Lambert, and T. M. Craig. 2013. Effect of using redberry juniper (Juniperus pinchotii) to reduce Haemonchus contortus in vitro motility and increase ivermectin efficacy. Vet. Parasitol. 197:271-276. doi:10.1016/j.vetpar.2013.04.021

Asanuma, N., and T. Hino. 2002. Regulation of fermentation in a ruminal bacterium, Streptococcus bovis, with special reference to rumen acidosis. Anim. Sci. J. 73:313-325. doi:10.1046/j.13443941.2002.00044.x

Austin, P. J., L. A. Suchar, C. T. Robbins, and A. E. Hagerman. 1989. Tannin-binding proteins in saliva of deer and their absence in saliva of sheep and cattle. J. Chem. Ecol. 15:1335-1347. doi:10.1007/BF01014834

Babaei, Y., Y. Rouzbehan, and D. Alipour. 2015. Effect of rumen bacteria from sheep adapted to a tanninferous diet on in vitro fermentation parameters of pistachio hulls using bovine inoculum. Iran. J. Vet. Res. 16:357-362.

Baumgardt, B. R. 1964. Practical observations of the quantitative analysis of free volatile patty acids in aqueous solutions by gasliquid chromatography. Dep. Bull. I. Dep. of Dairy Sci., Univ. of Wisconsin-Madison, Madison.

Berger, D. S. 2015. GIDEON guide to medically important bacteria. GIDEON Informatics, Inc., Los Angeles, CA.

Boyle, R., S. McLean, W. J. Foley, and N. W. Davies. 1999. Comparative metabolism of dietary terpene, p-cymene, in generalist and specialist folivorous marsupials. J. Chem. Ecol. 25:2109-2126. doi:10.1023/A:1021092908058

Bozinovic, F., and F. F. Novoa. 1997. Metabolic costs of rodents feeding on plant chemical defenses: A comparison between an herbivore and an omnivore. Comp. Biochem. Physiol. Part A. Physiol. 117:511-514. doi:10.1016/S0300-9629(96)00409-4

Broderick, G. A., and J. H. Kang. 1980. Automated simultaneous determination of ammonia and total amino acids in ruminal fluid and in vitro media. J. Dairy Sci. 63:64-75. doi:10.3168/jds. S0022-0302(80)82888-8

Broudiscou, L.-P., A. Cornu, and A. Rouzeau. 2007. In vitro degradation of 10 mono- and sesquiterpenes of plant origin by caprine rumen micro-organisms. J. Sci. Food Agric. 87:1653-1658. doi:10.1002/jsfa. 2863

Burnham, K. P., and W. S. Overton. 1979. Robust estimation of population size when capture probabilities vary among animals. Ecology 60:927-936. doi:10.2307/1936861

Calsamiglia, S., M. Busquet, P.W. Cardozo, L. Castillejos, and A. Ferret. 2007. Invited review: Essential oils as modifiers of rumen microbial fermentation. J. Dairy Sci. 90:2580-2595. doi:10.3168/jds.2006-644 
Caporaso, J. G., C. L. Lauber, W. A. Walters, D. Berg-Lyons, C. A. Lozupone, P. J. Turnbaugh, N. Fierer, and R. Knight. 2011. Global patterns of $16 \mathrm{~S}$ rRNA diversity at a depth of millions of sequences per sample. Proc. Natl. Acad. Sci. U. S. A. 108:4516 4522. doi:10.1073/pnas.1000080107

de Carvalho, C. C. C. R., and M. M. R. da Fonseca. 2006. Biotransformation of terpenes. Biotechnol. Adv. 24:134-142. doi:10.1016/j.biotechadv.2005.08.004

Chao,A., and T.-J. Shen. 2003. Nonparametric estimation of Shannon's index of diversity when there are unseen species in sample Environ. Ecol. Stat. 10:429-443. doi:10.1023/A:1026096204727

Chao, A., and T.-J. Shen. 2010. Program SPADE (Species Prediction and Diversity Estimation). http://chao.stat.nthu.edu.tw/wordpress/software_download/softwarespader_online/

Chaves, A. V., K. Stanford, M. R. Dugan, L. L. Gibson, T. A. McAllister, F. Van Herk, and C. Benchaar. 2008. Effects of cinnamaldehyde, garlic and juniper berry essential oils on rumen fermentation, blood metabolites, growth performance, and carcass characteristics of growing lambs. Livest. Sci. 117:215-224. doi:10.1016/j.livsci.2007.12.013

Chen, W., C. K. Zhang, Y. Cheng, S. Zhang, and H. Zhao. 2013. A comparison of methods for clustering $16 \mathrm{~S}$ rRNA sequences into OTUs. PLoS One 8:e70837. doi:10.1371/journal.pone.0070837

Clarke, K.R. 2006. PRIMER v6: User manual/tutorial. Plymouth Mar. Lab., Plymouth, UK.

Cobellis, G., Z. Yu, C. Forte, G. Acuti, and M. Trabalza-Marinucci. 2016. Dietary supplementation of Rosmarinus officinalis L. leaves in sheep affects the abundance of rumen methanogens and other microbial populations. J. Anim. Sci. Biotechnol. 7:27. doi:10.1186/s40104-016-0086-8

Dawdy, L., S. L. Lodge-Ivey, J. Browne-Silva, C. Roof, and M. K. Petersen. 2009. Effect of Juniperus monosperma on rumen bacterial diversity. In: 62nd Society for Range Management Annual Meeting. Soc. for Range Manage., Albuquerque, NM. p. 2030-2032.

Dearing, M. D., W. J. Foley, and S. McLean. 2005. The influence of plant secondary metabolites on the nutritional ecology of herbivorous terrestrial vertebrates. Annu. Rev. Ecol. Evol. Syst. 36:169-189. doi:10.1146/annurev.ecolsys.36.102003.152617

Dehority, B. A. 1966. Characterization of several bovine rumen bacteria isolated with a xylan medium. J. Bacteriol. 91:1724-1729.

Dickey, A. M., J. D. Loy, J. L. Bono, T. P. L. Smith, M. D. Apley, B. V. Lubbers, K. D. DeDonder, S. F. Capik, R. L. Larson, B. J. White, J. Blom, C. G. Chitko-McKown, and M. L. Clawson. 2016. Large genomic differences between Moraxella bovoculi isolates acquired from the eyes of cattle with infectious bovine keratoconjunctivitis versus the deep nasopharynx of asymptomatic cattle. Vet. Res. (Faisalabad) 47:31. doi:10.1186/s13567016-0316-2

Downes, J., S. R. Vartoukian, F. E. Dewhirst, J. Izard, T. Chen, W.-H. Yu, I. C. Sutcliffe, and W. G. Wade. 2009. Pyramidobacter piscolens gen. nov., sp. nov., a member of the phylum "Synergistetes" isolated from the human oral cavity. Int. J. Syst. Evol. Microbiol. 59:972-980. doi:10.1099/ijs.0.000364-0

Dziba, L. E., J. O. Hall, and F. D. Provenza. 2006. Feeding behavior of lambs in relation to kinetics of 1,8-cineole dosed intravenously or into the rumen. J. Chem. Ecol. 32:391-408. doi:10.1007/ s10886-005-9009-4

Edgar, R. C., B. J. Haas, J. C. Clemente, C. Quince, and R. Knight. 2011. UCHIME improves sensitivity and speed of chimera detection. Bioinformatics 27:2194-2200. doi:10.1093/bioinformatics/btr381

Elmastaş, M., İ. Gülçin, Ş. Beydemir, Ö. İrfan Küfrevioğlu, and H. Y. Aboul-Enein. 2006. A study on the in vitro antioxidant activity of juniper (Juniperus communis L.) fruit extracts. Anal. Lett. 39:47-65. doi:10.1080/00032710500423385
Farmer, C. G., B. C. Woods, R. C. Cochran, J. S. Heldt, C. P. Mathis, K. C. Olson, E. C. Titgemeyer, and T. A. Wickersham. 2004. Effect of supplementation frequency and supplemental urea level on dormant tallgrass-prairie hay intake and digestion by beef steers and prepartum performance of beef cows grazing dormant tallgrass-prairie. J. Anim. Sci. 82:884-894. doi: $10.2527 / 2004.823884 x$

Fritz, J. S., and G. H. Schenk. 1979. Quantitative analytical chemistry. Allyn and Bacon, Inc, Boston, MA.

Good, I. J. 1953. On population frequencies of species and the estimation of population parameters. Biometrika 40:237-264. doi:10.1093/biomet/40.3-4.237

Gregg, K., C. L. Cooper, D. J. Schafer, H. Sharpe, C. E. Beard, G. Allen, and J. Xu. 1994. Detoxification of the plant toxin fluoroacetate by a genetically modified rumen bacterium. Biotechnology (N. Y.) 12:1361-1365.

van Gylswyk, N. O. 1995. Succiniclasticum ruminis gen. nov., sp. nov., a ruminal bacterium converting succinate to propionate as the sole energy-yielding mechanism. Int. J. Syst. Bacteriol. 45:297-300. doi:10.1099/00207713-45-2-297

Holdeman, L. V., E. P. Cato, and W. E. C. Moore. 1977. Anaerobe laboratory manual. Virginia Polytechnic Inst. and State Univ., Blacksburg, VA.

Holman, D. B., E. Timsit, T. W. Alexander, R. Knight, and R. Knight. 2015. The nasopharyngeal microbiota of feedlot cattle. Sci. Rep. 5:15557. doi:10.1038/srep 15557

Ishaq, S. L., S. P. Johnson, Z. J. Miller, E. A. Lehnhoff, S. Olivo, C. J. Yeoman, and F. D. Menalled. 2017. Impact of cropping systems, soil inoculum, and plant species identity on soil bacterial community structure. Microb. Ecol. 73:417-434. doi:10.1007/ s00248-016-0861-2

Jost, L. 2006. Entropy and diversity. Oikos 113:363. doi:10.1111/ j.2006.0030-1299.14714.x

Karchesy, J. 1998. The literature of juniper utilization for oils and specialty products: A report to the western juniper steering committee. Oregon State Univ., Corvallis, OR.

Kasperowicz, A. 1994. Comparison of utilization of pectins from various sources by pure cultures of pectinolytic rumen bacteria and mixed cultures of rumen microorganisms. Acta Microbiol. Pol. 43:47-56.

Koedam, A., and A. Looman. 2008. Effect of $\mathrm{pH}$ during distillation on the composition of the volatile oil from Juniperus sabina. Planta Med. 40:22-28. doi:10.1055/s-2008-1074997

Kohl, K. D., and M. D. Dearing. 2012. Experience matters: Prior exposure to plant toxins enhances diversity of gut microbes in herbivores. Ecol. Lett. 15:1008-1015. doi:10.1111 /j.1461-0248.2012.01822.

Kohl, K. D., and M. D. Dearing. 2016. The woodrat gut microbiota as an experimental system for understanding microbial metabolism of dietary toxins. Front. Microbiol. 7:1165. doi:10.3389/ fmicb.2016.01165

Kozich, J. J., S. L. Westcott, N. T. Baxter, S. K. Highlander, and P. D. Schloss. 2013. Development of a dual-index sequencing strategy and curation pipeline for analyzing amplicon sequence data on the MiSeq Illumina sequencing platform. Appl. Environ. Microbiol. 79:5112-5120. doi:10.1128/AEM.01043-13

Langille, M. G. I., J. Zaneveld, J. G. Caporaso, D. McDonald, D. Knights, J. A. Reyes, J. C. Clemente, D. E. Burkepile, R. L. Vega Thurber, R. Knight, R. G. Beiko, and C. Huttenhower. 2013. Predictive functional profiling of microbial communities using 16S rRNA marker gene sequences. Nat. Biotechnol. 31:814-821. doi: $10.1038 /$ nbt.2676

Lozupone, C., and R. Knight. 2005. UniFrac: A new phylogenetic method for comparing microbial communities. Appl. Environ. Microbiol. 71:8228-8235. doi:10.1128/AEM.71.12.82288235.2005

Lüddeke, F., A. Wülfing, M. Timke, F. Germer, J. Weber, A. Dikfidan, T. Rahnfeld, D. Linder, A. Meyerdierks, and J. Harder. 2012. Geraniol and geranial dehydrogenases induced in anaerobic monoterpene degradation by Castellaniella defragrans. Appl. Environ. Microbiol. 78:2128-2136. doi:10.1128/AEM.0722611 
Malecky, M., H. Albarello, and L. P. Broudiscou. 2012. Degradation of terpenes and terpenoids from Mediterranean rangelands by mixed rumen bacteria in vitro. Animal 6:612-616. doi:10.1017/ S1751731111001947

Malecky, M., and L. P. Broudiscou. 2009. Disappearance of nine monoterpenes exposed in vitro to the rumen microflora of dairy goats: Effects of inoculum source, redox potential, and vancomycin. J. Anim. Sci. 87:1366-1373. doi:10.2527/jas.2008-1419

Masella, A. P., A. K. Bartram, J. M. Truszkowski, D. G. Brown, and J. D. Neufeld. 2012. PANDAseq: Paired-end assembler for Illumina sequences. BMC Bioinformatics 13:31. doi:10.1186/1471-2105-13-31

McLister, J. D., J. S. Sorensen, and M. D. Dearing. 2004. Effects of consumption of juniper (Juniperus monosperma) on cost of thermoregulation in the woodrats Neotoma albigula and Neotoma stephensi at different acclimation temperatures. Physiol. Biochem. Zool. 77:305-312. doi:10.1086/380211

Miller, A. W., K. D. Kohl, and M. D. Dearing. 2014. The gastrointestinal tract of the white-throated woodrat (Neotoma albigula) harbors distinct consortia of oxalate-degrading bacteria. Appl. Environ. Microbiol. 80:1595-1601. doi:10.1128/AEM.03742-13

Muyzer, G., E. C. de Waal, and A. G. Uitterlinden. 1993. Profiling of complex microbial populations by denaturing gradient gel electrophoresis analysis of polymerase chain reaction-amplified genes coding for 16S rRNA. Appl. Environ. Microbiol. 59:695-700

Palo, R. T., and C. T. Robbins (Ed.) 1991. Plant defenses against mammalian herbivory. CRC Press, Boston, MA.

Patra, A. K. 2015. Urea/ammonia metabolism in the rumen and toxicity in ruminants In: Rumen microbiology: From evolution to revolution. Springer India, New Delhi. p. 329-341, doi:10.1007/978-81-322-2401-3 22.

Patra, A. K., and Z. Yu. 2012. Effects of essential oils on methane production and fermentation by, and abundance and diversity of, rumen microbial populations. Appl. Environ. Microbiol. 78:4271-4280. doi:10.1128/AEM.00309-12

Patra, A. K., and Z. Yu. 2015. Essential oils affect populations of some rumen bacteria in vitro as revealed by microarray (RumenBactArray) analysis. Front. Microbiol. 6:297. doi: $10.3389 /$ fmicb. 2015.00297

Pritz, R. K., K. L. Launchbaugh, and C. A. Taylor, Jr. 1997. Effects of breed and dietary experience on juniper consumption by goats. J. Range Manage. 50:600-606. doi:10.2307/4003454

Quast, C., E. Pruesse, P. Yilmaz, J. Gerken, T. Schweer, P. Yarza, J. Peplies, and F. O. Glöckner. 2013. The SILVA ribosomal RNA gene database project: Improved data processing and web-based tools. Nucleic Acids Res. 41:D590-D596. doi:10.1093/nar/ gks1219

Quinn, J. C., A. Kessell, and L. A. Weston. 2014. Secondary plant products causing photosensitization in grazing herbivores: Their structure, activity and regulation. Int. J. Mol. Sci. 15:1441-1465. doi:10.3390/ijms15011441

R Core Team. 2015. R: A language and environment for statistical computing. R Found. Stat. Comput., Vienna.

Schloss, P. D., S. L. Westcott, T. Ryabin, J. R. Hall, M. Hartmann, E. B. Hollister, R. A. Lesniewski, B. B. Oakley, D. H. Parks, C. J. Robinson, J. W. Sahl, B. Stres, G. G. Thallinger, D. J. Van Horn, and C. F. Weber. 2009. Introducing mothur: Open-source, platform-independent, community-supported software for describing and comparing microbial communities. Appl. Environ. Microbiol. 75:7537-7541. doi:10.1128/AEM.01541-09

Schwartz, C. C., J. G. Nagy, and W. L. Regelin. 1980. Juniper oil yield, terpenoid concentration, and antimicrobial effects on deer. J. Wildl. Manage. 44:107-113. doi:10.2307/3808356

Scott, R., N. Yarlett, K. Hillman, A. G. Williams, D. Lloyd, and T. N. Williams. 1983. The presence of oxygen in rumen liquor and its effects on methanogenesis. J. Appl. Bacteriol. 55:143-149. doi:10.1111/j.1365-2672.1983.tb02658.x
Segata, N., S. K. Haake, P. Mannon, K. P. Lemon, L. Waldron, D. Gevers, C. Huttenhower, and J. Izard. 2012. Composition of the adult digestive tract bacterial microbiome based on seven mouth surfaces, tonsils, throat and stool samples. Genome Biol. 13:R42. doi:10.1186/gb-2012-13-6-r42

Shannon, C. E., and W. Weaver. 1949. The mathematical theory of communication. University of Illinois Press, Urbana.

Stewart, W. C., T. R. Whitney, E. J. Scholljegerdes, H. D. Naumann, N. M. Cherry, J. P. Muir, B. D. Lambert, J. W. Walker, R. P. Adams, K. D. Welch, D. R. Gardner, and R. E. Estell. 2015. Effects of Juniperus species and stage of maturity on nutritional, in vitro digestibility, and plant secondary compound characteristics. J. Anim. Sci. 93:4034-4047. doi:10.2527/jas.2015-9274

Taylor, C. A., J. E. Huston, N. E. Garza, T. D. Brooks, and R. A. Moen. 1994. Use of juniper as a supplemental feed limiter. In: Sheep and Goat, Wool and Mohar Rep. Texas A\&M Exp. Stat. Rep., College Station, TX. p. 31-33.

Vaithiyanathan, S., Q. Sheikh, and R. Kumar. 2005. Effect of transinoculation of goat rumen liquor on degradation and metabolism of mimosine in sheep fed with Leucaena leucocephala leaves. Asian-Austr. J. Anim. Sci. 18:332-339. doi:10.5713/ ajas.2005.332

Vartoukian, S. R., J. Downes, R. M. Palmer, and W. G. Wade. 2013. Fretibacterium fastidiosum gen. nov., sp. nov., isolated from the human oral cavity. Int. J. Syst. Evol. Microbiol. 63:458-463. doi:10.1099/ijs.0.041038-0

Wallace, R. J. 2004. Antimicrobial properties of plant secondary metabolites. Proc. Nutr. Soc. 63:621-629. doi:10.1079/ PNS2004393

Wang, Q., G. M. Garrity, J. M. Tiedje, and J. R. Cole. 2007. Naïve Bayesian classifier for rapid assignment of rRNA sequences into the new bacterial taxonomy. Appl. Environ. Microbiol. 73:5261-5267. doi:10.1128/AEM.00062-07

Whitney, T. R. 2017. Ground Juniperus pinchotii and urea in supplements fed to Rambouillet ewe lambs: I. Feedlot growth traits, blood serum parameters, and fecal characteristics. J. Anim. Sci. 95:3676-3686. doi:10.2527/jas.2017.1419

Whitney, T. R., C. J. Lupton, J. P. Muir, R. P. Adams, and W. C. Stewart. 2014. Effects of using ground redberry juniper and dried distillers grains with solubles in lamb feedlot diets: Growth, blood serum, fecal, and wool characteristics. J. Anim. Sci. 92:1119-1132. doi:10.2527/jas.2013-7007

Whitney, T. R., C. J. Lupton, and S. B. Smith. 2011. Redberry juniper as a roughage source in lamb feedlot rations: Wool and carcass characteristics, meat fatty acid profiles, and sensory panel traits. Meat Sci. 89:160-165. doi:10.1016/j.meatsci.2011.04.010

Whitney, T. R., S. Wildeus, and A. M. Zajac. 2013. The use of redberry juniper (Juniperus pinchotii) to reduce Haemonchus contortus fecal egg counts and increase ivermectin efficacy. Vet. Parasitol. 197:182-188. doi:10.1016/j.vetpar.2013.06.010

Yang, W. Z., C. Benchaar, B. N. Ametaj, A. V. Chaves, M. L. He, and T. A. McAllister. 2007. Effects of garlic and juniper berry essential oils on ruminal fermentation and on the site and extent of digestion in lactating cows. J. Dairy Sci. 90:5671-5681. doi:10.3168/jds.2007-0369

Yesilbag, D., H. Biricik, I. Cetin, C. Kara, Y. Meral, S. S. Cengiz, A. Orman, and D. Udum. 2016. Effects of juniper essential oil on growth performance, some rumen protozoa, rumen fermentation and antioxidant blood enzyme parameters of growing Saanen kids. J. Anim. Physiol. Anim. Nutr. doi:10.1111/jpn.12560

Zhu, Z., S. Hang, S. Mao, and W. Zhu. 2014. Diversity of Butyrivibrio group bacteria in the rumen of goats and its response to the supplementation of garlic oil. Asian-Austr. J. Anim. Sci. 27:179186. doi:10.5713/ajas.2013.13373 